\title{
The Phosphonium Ion Efflux System of Escherichia coli: Relationship to the Ethidium Efflux System and Energetic Studies
}

\author{
By MELVIN MIDGLEY \\ Department of Biochemistry, University of Hull, Hull HU6 7RX, UK
}

(Received 10 February 1986; revised 2 June 1986)

The extent of accumulation of methyltriphenylphosphonium ion by Escherichia coli was shown to be dependent on the permeability of the outer membrane and the activity of an efflux system for this compound. Evidence consistent with the operation of a single efflux system for compounds such as phosphonium ions, phenanthridiniums and flavines is presented. Studies on the energy coupling mechanism for this efflux system indicated that it was driven by the transmembrane proton electrochemical gradient.

\section{INTRODUCTION}

Measurement of the distribution of phosphonium ions, such as methyltriphenylphosphonium ion (MTP) and tetraphenylphosphonium ion (TPP), has been used to estimate the magnitude of the membrane potential $(\Delta \psi)$ in a number of biological systems (Rottenberg, 1975) including bacteria (Kashket, 1985). Arthrobacter globiformis and Acinetobacter calcoaceticus possess an energy-linked efflux system for phosphonium ions and related compounds such as tetraphenylarsonium ion (TPA) and crystal violet (Midgley et al., 1985, 1986a), and Escherichia coli possesses an efflux system for which phosphonium ions are a substrate (Midgley et al., 1986 b). The existence in $E$. coli of an efflux system capable of extruding other complex cations has been shown from studies of the interaction of this organism with acriflavine (Nakamura, 1966, 1967; Silver et al., 1968; Kushner \& Khan, 1968) and ethidium (Lambert \& Le Pecq, 1984; Jones \& Midgley, 1985).

The aims of the work presented here were to confirm the fluorimetric assay (Midgley et al., $1986 b$ ) for the existence of a phosphonium ion efflux system using isotopic assays, examine the relationship between the phosphonium ion efflux system and those previously detected and investigate the energy-coupling mechanism of the efflux system.

\section{METHODS}

Growth and harvesting of the organism. Escherichia coli AN 249, an unc A mutant (Cox et al., 1973), was grown and harvested as described by Midgley et al. (1986b). All experiments were done using $20 \mathrm{~mm}-\mathrm{HEPES} / \mathrm{NaOH}$ buffer (pH 7.0).

Phosphonium ion accumulation. This was measured using a rapid filtration technique (Midgley \& Dawes, 1973). The organism was incubated aerobically at $37^{\circ} \mathrm{C}$ at a cell density of $0.5 \mathrm{mg}$ dry wt $\mathrm{ml}^{-1}$. All assays were done in duplicate. Uptake was corrected for extracellular and filter binding using a control incubated on ice in the absence of glucose or formate. For experiments using 1 or $5 \mu \mathrm{M}-\mathrm{MTP}$ this value was typically 0.02 or $0.05 \mu \mathrm{mol}(\mathrm{g} \text { dry wt })^{-1}$, respectively. Unless otherwise stated the concentration of MTP used in isotopic experiments was $1 \mu \mathrm{M}$ [specific activity $125 \mu \mathrm{Ci} \mu \mathrm{mol}^{-1}\left(4.625 \mathrm{MBq} \mu \mathrm{mol}^{-1}\right)$ ]. In situ treatment with EDTA was achieved by addition of $0.3 \mathrm{mM}$ EDTA directly to the incubation mixture. Further details are given in the appropriate figure legends.

Abbreviations: $\Delta \psi$, (plasma) membrane potential; $\Delta p$, proton-motive force (proton electrochemical gradient in $\mathrm{mV}) ; \Delta \bar{\mu}$, electrochemical gradient; MTP, methyltriphenylphosphonium ion; TPP, tetraphenylphosphonium ion; TPA, tetraphenylarsonium ion; DMP, 2-(dimethylaminostyryl)-1-ethylpyridinium; CCCP, carbonyl cyanide $m$ chlorophenylhydrazone; IAA, iodoacetate. 
Ethidium efflux. This was measured using a fluorimetric and an isotopic assay as described by Jones \& Midgley (1985), except that $20 \mathrm{mM}-\mathrm{HEPES} / \mathrm{NaOH}(\mathrm{pH} \mathrm{7.0)}$ was used throughout. Cells were loaded with ethidium (5 $\mu \mathrm{M})$ as previously described except that buffer was used throughout (Lambert \& Le Pecq, 1984; Jones \& Midgley, 1985). In the fluorimetric assay, aerobic conditions were maintained by adding $\mathrm{H}_{2} \mathrm{O}_{2}(0.016 \%$ vol. final concentration) along with substrate (glucose or sodium formate).

Fluorimetric measurements using DMP. These were made as described by Midgley et al. (1986b).

Energy-depleted cells. These were prepared by incubating the cells $\left(10 \mathrm{mg} \mathrm{dry} \mathrm{wt} \mathrm{ml}^{-1}\right)$ aerobically at $37^{\circ} \mathrm{C}$ in the presence of $40 \mu \mathrm{M}-\mathrm{CCCP}$ for $1 \mathrm{~h}$. The cell suspension $(10 \mathrm{ml})$ was then slowly cooled and diluted to $40 \mathrm{ml}$ with buffer. The cells were sedimented, resuspended in $40 \mathrm{ml}$ of buffer and again sedimented before resuspension in $2 \mathrm{ml}$ of buffer.

Respiration studies. These were done at $37^{\circ} \mathrm{C}$ using a Rank oxygen electrode. The cell density was 0.25 or $0.5 \mathrm{mg}$ dry wt $\mathrm{ml}^{-1}$.

Chemicals and radiochemicals. These were obtained from sources specified by Midgley et al. (1986a) and Jones \& Midgley (1985).

\section{RESULTS}

Isotopic demonstration of MTP efflux

Washed cells of $E$. coli AN 249 incubated with $5 \mu \mathrm{M}$-MTP in the absence of an added energy source accumulated MTP (Fig. 1). This uptake was prevented by the prior addition of glucose which also supported the efflux of accumulated MTP (Fig. 1), and was inhibited by $40 \mu \mathrm{M}$ CCCP (data not shown). Glucose stimulated respiration approximately 14 -fold to $54 \mu \mathrm{mol} \mathrm{O}_{2}$ consumed $\min ^{-1}$ (g dry wt) ${ }^{-1}$.

\section{Factors affecting the net influx of MTP}

A series of experiments was done to demonstrate the relationship of the net influx of MTP to the presence of putative substrates of the efflux system. In addition, the effect of an energy source and changes in the outer membrane permeability (produced by in situ EDTA treatment) on the relationship were investigated. Net influx of MTP was stimulated by $10 \mu \mathrm{M}$-TPP in the absence of an added energy source (Fig. 2), and $10 \mu \mathrm{M}$-TPA, $10 \mu \mathrm{M}$-euflavine or $10 \mu \mathrm{M}$-ethidium bromide stimulated MTP uptake by 9-, 5.5- and 2-7-fold respectively, measured after $30 \mathrm{~min}$. The absolute value of the control in the absence of an added energy source was $0.078 \mu$ mol MTP ( $\mathrm{g}$ dry wt) ${ }^{-1}$. The uptake of MTP in the presence of TPP was inhibited by $40 \mu \mathrm{M}-\mathrm{CCCP}$ (data not shown).

A stimulation of MTP uptake by TPP was not observed in the presence of glucose (Fig. 2). TPP $(10 \mu \mathrm{M})$ was accumulated to $<0.2$ and $3.8 \mu \mathrm{mol}$ TPP ( $\mathrm{g}$ dry wt $)^{-1}$ after $40 \mathrm{~min}$, in the presence and absence of glucose, respectively. If the cells were treated in situ with EDTA the stimulatory effect was again observed. Cells incubated with $1 \mu \mathrm{M}-\mathrm{MTP}$ and glucose plus EDTA or glucose, EDTA and $10 \mu \mathrm{M}$-TPP accumulated at the steady state 0.018 or $0.22 \mu$ mol MTP (g dry wt) ${ }^{-1}$, respectively, and cells incubated with $10 \mu \mathrm{M}$-TPP accumulated 0.07 or $2.7 \mu \mathrm{mol}$ TPP ( $\mathrm{g}$ dry $\mathrm{wt})^{-1}$ in the presence of glucose or glucose plus EDTA, respectively.

The uptake of MTP by EDTA-treated cells in the presence of glucose and TPP was inhibited by $40 \mu \mathrm{M}-\mathrm{CCCP}$ (data not shown).

\section{Relationship of the phosphonium ion efflux system to the ethidium efflux system}

The stimulation of net MTP influx by ethidium was consistent with these two compounds sharing a common efflux system. Since it is possible to measure unidirectional efflux of ethidium from cells suitably loaded with this compound (Lambert \& Le Pecq, 1984; Jones \& Midgley, 1985), and since effects on unidirectional fluxes are easier to interpret, this relationship was further investigated. Using either a fluorimetric assay (Fig. $3 a$ ) or an isotopic assay (Fig. $3 b$ ) TPP, TPA and MTP were demonstrated to inhibit ethidium efflux.

The loading process involves a brief treatment with CCCP which was apparently sufficient to deplete the cells of an energy supply as ethidium efflux was substrate dependent, and could be driven by either glucose (Fig. $4 a, b$ ) or formate (Fig. $3 a, b$ ). The inhibitory effect of TPA, TPP and MTP was not attributable to inhibition of respiration; $10 \mathrm{mM}$-sodium formate supported a 


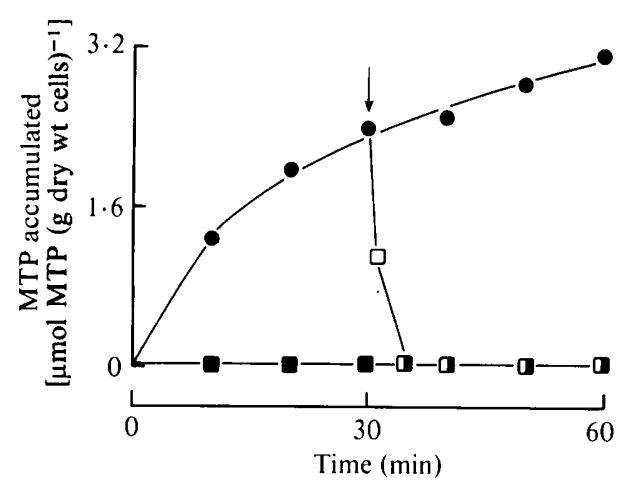

Fig. 1

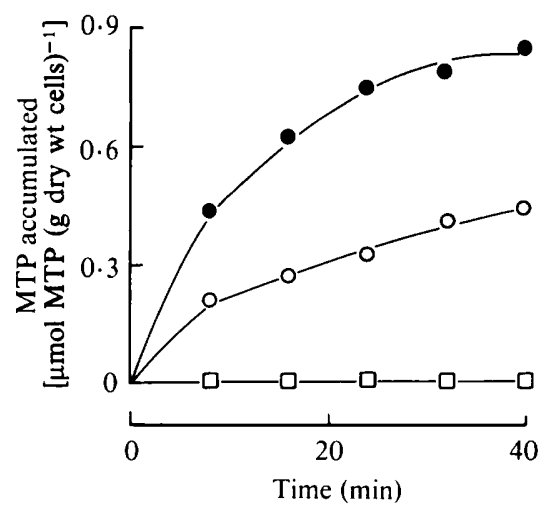

Fig. 2

Fig. 1. Substrate-induced efflux of MTP from $E$. coli AN 249. MTP uptake was assayed as described in Methods except that $5 \mu \mathrm{M}$-MTP was used under the following conditions: $\bigcirc$, no substrate added; $\square$, plus $10 \mathrm{~mm}$-glucose as indicated by the arrow; $\square$, plus $10 \mathrm{~mm}$-glucose throughout.

Fig. 2. Stimulation of MTP accumulation by TPP in E. coli AN 249. MTP uptake was assayed as described in Methods under the following conditions: $\bigcirc$, no addition; $O$, plus $10 \mu \mathrm{M}-\mathrm{TPP} ; \square$, plus $10 \mathrm{mM}$-glucose or plus $10 \mathrm{mM}$-glucose and $10 \mu \mathrm{M}$-TPP.
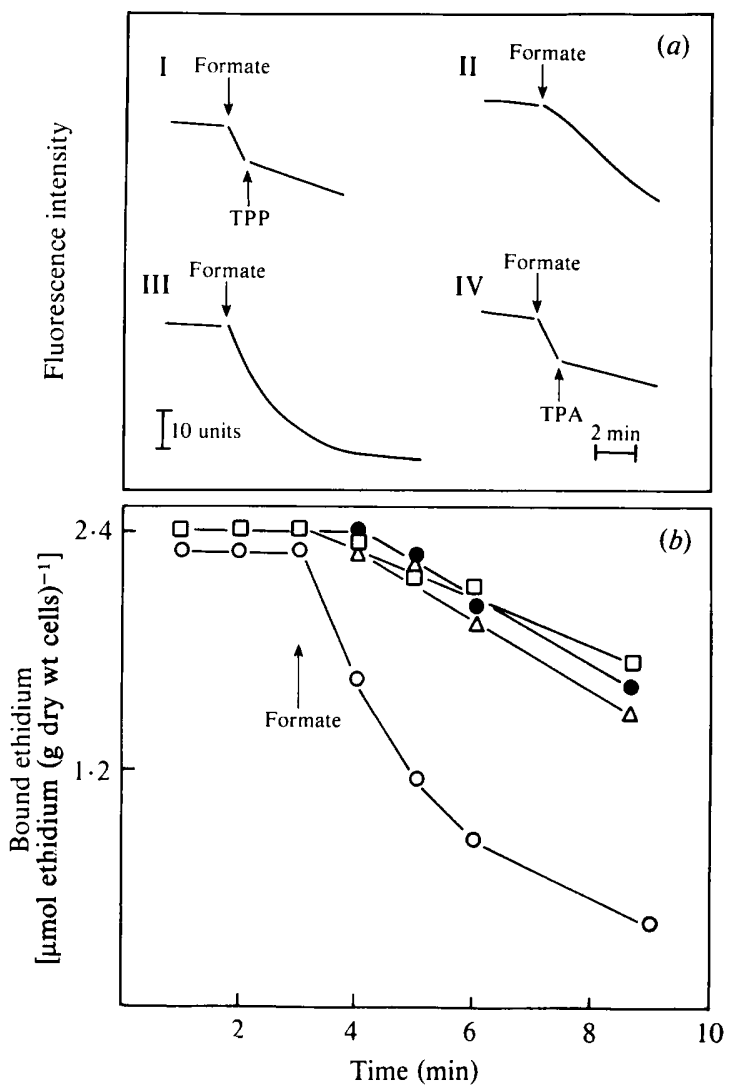

Fig. 3. Effect of MTP, TPP and TPA on the efflux of ethidium from $E$. coli AN 249. (a) Fluorimetric assay. In traces I and IV the concentration of TPP and TPA was $10 \mu \mathrm{M}$. For trace II $30 \mu \mathrm{M}-\mathrm{MTP}$ was added before $10 \mathrm{mM}$-sodium formate. Trace III is the control, with no addition other than formate. The traces are offset for the purpose of display. (b) Isotopic assay. Efflux of ethidium was assayed as described in Methods under the following conditions: $O$, no addition; $O$, plus $10 \mu \mathrm{M}-\mathrm{TPA} ; \triangle$, plus $50 \mu \mathrm{M}$-MTP; $\square$, plus $10 \mu \mathrm{M}$-TPP. In all cases efflux was initiated by the addition of 10 mM-sodium formate as indicated by the arrow. For clarity the initial phase in the presence of MTP and TPA is not shown. 


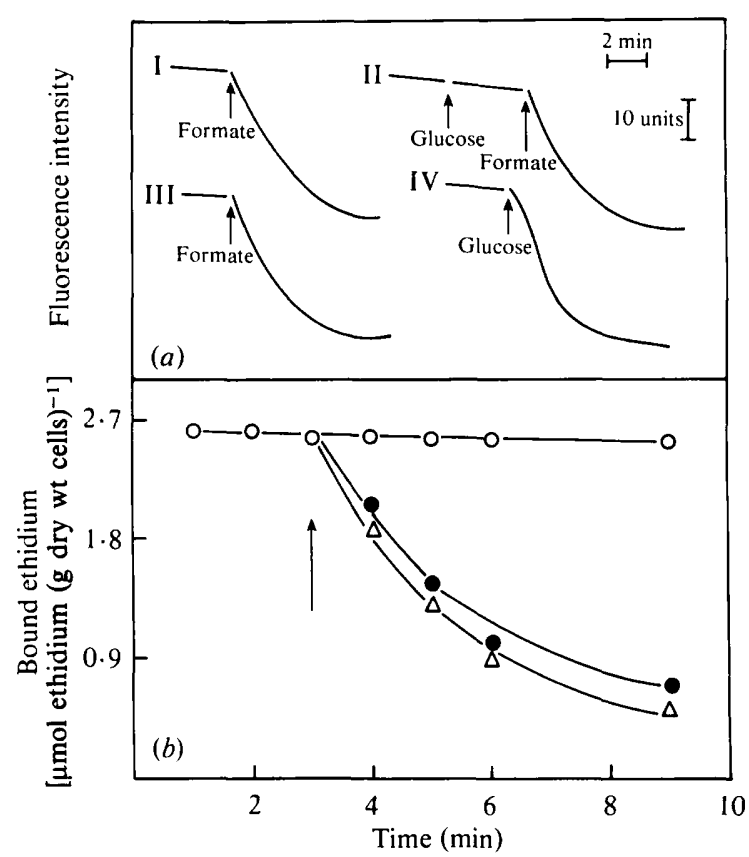

Fig. 4. Energetics of ethidium efflux from $E$. coli AN 249. (a) Fluorimetric assay. In traces II and III IAA $(5 \mathrm{mM})$ was present throughout the incubation. Substrate $(10 \mathrm{mM})$ was added as indicated. Traces I and IV are the controls and received no additions other than those indicated. The traces are offset for the purpose of display. (b) Isotopic assay. Efflux of ethidium was assayed as described in Methods under the following conditions: $O$, no addition throughout, or plus 5 mM-IAA throughout and 10 mM-glucose as indicated by the arrow; $\bigcirc$, plus $10 \mathrm{~mm}$-glucose as indicated by the arrow; $\triangle$, presence or absence of 5 mM-IAA throughout and $10 \mathrm{~mm}$-sodium formate as indicated by the arrow.

rate of respiration of $189 \mu \mathrm{mol} \mathrm{O}_{2} \min ^{-1}(\mathrm{~g} \mathrm{dry} \mathrm{wt})^{-1}$, and this was not affected by the addition of $50 \mu \mathrm{M}-\mathrm{MTP}$ or $10 \mu \mathrm{M}$-TPP or $10 \mu \mathrm{M}$-TPA. The endogenous rate of respiration was $<11 \mu \mathrm{mol} \mathrm{O}$ $\min ^{-1}(\mathrm{~g} \text { dry wt) })^{-1}$.

\section{Energetics of ethidium and phosphonium ion efflux}

Glucose-driven efflux of ethidium was inhibited by $5 \mathrm{~mm}$-iodoacetate (IAA) while formatedriven efflux was insensitive to this compound (Fig. 4). IAA caused severe inhibition of glucosesupported respiration $(>90 \%$ ), but not of respiration supported by formate. In the presence of glucose or formate the rate of respiration, measured using cells loaded with ethidium, was 62 or $180 \mu \mathrm{mol} \mathrm{O} \mathrm{Omin}^{-1}(\mathrm{~g} \mathrm{dry} \mathrm{wt})^{-1}$, respectively. The endogenous rate was $<6 \mu \mathrm{mol} \mathrm{O}_{2} \mathrm{~min}^{-1}$ (g dry $w t)^{-1}$.

Since $E$. coli AN 249 is an unc mutant and therefore cannot produce ATP by oxidative phosphorylation, $\Delta \bar{\mu}_{\mathrm{H}^{+}}$was sufficient to drive ethidium efflux. Both glucose- and formatedriven efflux were inhibited by $40 \mu \mathrm{M}-\mathrm{CCCP}$; this concentration of uncoupler did not inhibit formate oxidation (data not shown).

Evidence that the phosphonium ion efflux system was operative under the conditions where only a $\Delta \bar{\mu}_{\mathrm{H}^{+}}$was generated was provided by isotopic experiments using MTP (Fig. 5) and fluorimetric experiments using DMP as a substrate (Fig. 6) (Midgley et al., 1986b). Cells of $E$. coli AN 249 were starved aerobically for $1 \mathrm{~h}$ in the presence of $40 \mu \mathrm{M}-\mathrm{CCCP}$, a treatment that diminished respiration to undetectable levels. Although the possibility that the cells retained some CCCP was not excluded, cells treated in this manner showed no uptake of MTP in the absence of substrate in the presence or absence of $10 \mu \mathrm{M}$-TPP (data not shown). In the presence of $10 \mathrm{mM}$-sodium formate, $10 \mu \mathrm{M}$-TPP stimulated net influx of MTP, and this was largely 


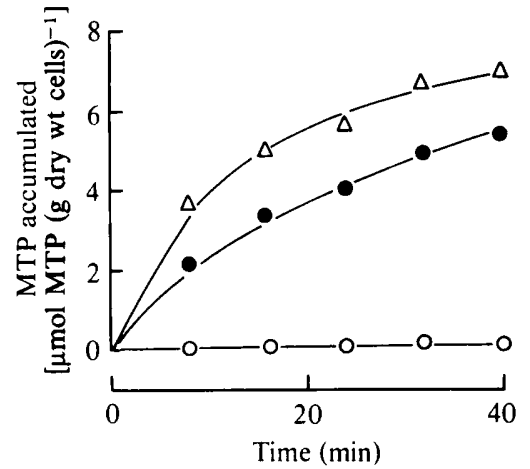

Fig. 5. Interaction of phosphonium ions with energy-depleted $E$. coli AN 249. Cells were starved and assayed for MTP uptake as described in Methods under the following conditions: $O$, plus $10 \mathrm{mM}^{-}$ sodium formate or $10 \mathrm{mM}$-sodium formate plus $5 \mathrm{mM}$-IAA; $\triangle$, plus $10 \mathrm{mM}$-sodium formate and $10 \mu \mathrm{M}$ TPP; 0 , plus $10 \mathrm{mM}$-sodium formate, $10 \mu \mathrm{M}$-TPP and $5 \mathrm{~mm}$-iodoacetate.

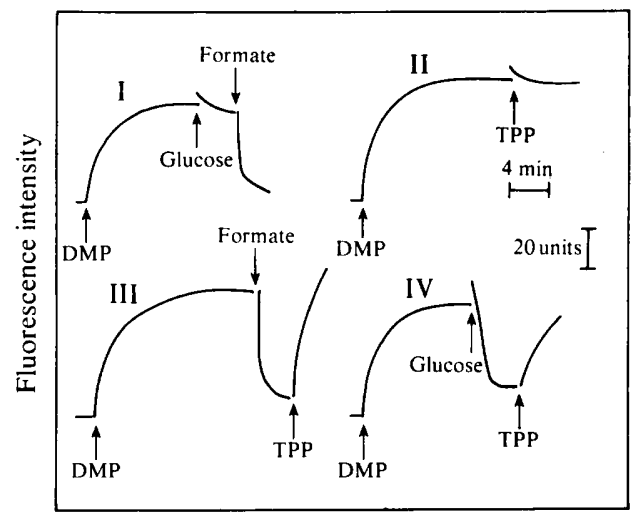

Fig. 6. Interaction of DMP with starved E. coli AN 249. Cells were starved and assayed for fluorimetric interaction with DMP as described in Methods. The concentrations used were $5 \mu \mathrm{M}$-DMP, $10 \mu \mathrm{M}$-TPP, $10 \mathrm{~mm}$-glucose and $10 \mathrm{~mm}$-sodium formate. The incubation mixture for trace I contained $5 \mathrm{mM}$-IAA throughout. The traces are offset for the purpose of display.

unaffected by the addition of 5 mM-IAA (Fig. 5); in the presence and absence of IAA the rate of respiration was equivalent to that supported by formate in unstarved cells $\left[180 \mu \mathrm{mol} \mathrm{O} \mathrm{min}^{-1}\right.$ $\left.(\mathrm{g} \text { dry } w)^{-1}\right]$.

DMP efflux could be driven in starved cells by glucose or formate; glucose-driven efflux, but not that driven by formate, was sensitive to IAA (Fig. 6). The stimulation of DMP fluorescence, previously suggested to arise from a stimulation of net influx due to an inhibition of DMP efflux (Midgley et al., 1986b), was not observed in starved cells unless glucose or formate were added (Fig. 6).

\section{DISCUSSION}

The observations presented in this paper confirm the conclusions drawn from fluorimetric studies using DMP as a probe for the phosphonium ion efflux system (Midgley et al., 1986 b). The increased fluorescence of DMP on addition of phosphonium ions to $E$. coli was attributed to an inhibition of a shared efflux system, leading to an increased net influx. This interpretation is supported by the observation of a substrate-induced efflux of MTP (Fig. 1). The stimulation of 
respiration accompanying the addition of glucose would predict an increase in $\Delta \bar{\mu}_{M T P}$, due to an increase in the $\Delta \psi$ component of the $\Delta \bar{\mu}_{\mathrm{H}^{+}}$at this external $\mathrm{pH}$. A clear efflux phase was observed as seen with other organisms (Midgley et al., 1985, 1986a). Thus in the presence of an oxidizable substrate such as glucose or formate $E$. coli appears impermeable to phosphonium ions when its outer membrane is intact. Addition of putative substrates for the efflux system inhibits efflux of MTP and thus leads to a stimulation of net influx (Fig. 2). As previously discussed (Midgley $e t$ $a l ., 1986 a, b)$, the stimulation of net uptake of MTP by an analogue such as TPP can only be used as a positive criterion since many factors can govern the steady state intracellular concentration of such a compound. The stimulation of MTP uptake by ethidium, euflavine and TPA suggests that these compounds are substrates for this efflux system.

The rapid penetration of the organism by TPP and TPA, as shown by the rapid establishment of the inhibition of ethidium or DMP efflux (Figs $3 a$ and 6), indicates that isotopic studies underestimate the rate of influx since a net flux rather than a unidirectional one is measured. The relative contribution of the efflux system and the outer membrane in diminishing the uptake of phosphonium ions, and related toxic cations such as euflavine, is currently unknown.

The observations of a stimulation of net MTP influx by ethidium, and the inhibition of ethidium efflux by phosphonium ions and TPA (Fig. $3 a, b$ ), are consistent with a single efflux system operating to transport these compounds, as well as DMP, out of E. coli. This hypothesis is further supported by the isolation of ethidium-resistant mutants of $E$. coli N43, a strain that is susceptible to ethidium because it carries the acr $A$ mutation (Nakamura, 1965). These mutants are resistant to ethidium, while retaining the original mutation, due to a higher level of the efflux system. Such mutants are also resistant to MTP (M. Midgley, unpublished observations). Ethidium efflux (Fig. 4) and DMP efflux (Fig. 6), and the stimulation of net MTP influx by TPP (Fig. 5), can occur in the presence of a $\Delta \bar{\mu}_{\mathrm{H}^{+}}$and ATP does not appear to have a significant role. Similar findings (I. G. Jones \& M. Midgley, unpublished observations) have been made for the ethidium resistance determinant previously cloned from a staphylococcal plasmid (Jones \& Midgley, 1985). A possible mechanism for these efflux systems could be an antiporter of the type $\mathrm{nX}^{+}$/ethidium, where $\mathrm{X}^{+}$is a suitable cation, e.g. $\mathrm{H}^{+}$. Further experiments, including testing the effect of adding cations other than $\mathrm{Na}^{+}$to the medium (as in the present work) will be of value.

The accumulation of phosphonium ions by $E$. coli corresponds to a steady state in which extrusion by an efflux system balances influx. This means that the accumulation ratio will be a function of at least the following possible variables: the outer membrane permeability, the permeability of the cytoplasmic membrane, the transmembrane $\Delta \psi$, the transmembrane $\Delta p$ (as a driving force for the efflux system), the surface potential at relevant membrane interfaces, the activity of the efflux system, and the concentration of the probe used. Thus many factors can be involved in determining the apparent $\Delta \psi$ as computed from the accumulation of phosphonium ions. The majority of these factors are subject to possible variation by, for example, changing the growth conditions, the strain of $E$. coli used, or the incubation medium used. In general it is likely that the operation of such an efflux system as described here will lead to underestimates of the $\Delta \psi$. In some cases, e.g. in vesicular systems in which the outer membrane has been removed, the operation of the efflux system may not play a significant role, but clearly much of the data derived from the application of these probes to bacteria (Kashket, 1985) will require reevaluation in the light of these findings. The models presented to explain the anomalous interaction of phosphonium ions with Bacillus subtilis were derived on the assumption that no active transport system played a role in the distribution of the probes used (Zaritsky et al., 1981). If an efflux system similar to that described in this work is present in $B$. subtilis then the increase in apparent $\Delta \psi$ recorded at increasing concentrations of the probe can be explained on the basis of an increasing contribution of the non-mediated fluxes to the steady state. This behaviour has been observed in $A$. calcoaceticus, an organism known to possess an efflux system for phosphonium ions (Midgley et al., 1986a). 


\section{REFERENCES}

Cox, G. B., Gibson, F. \& McCanN, L. (1973). Reconstitution of oxidative phosphorylation and the adenosine triphosphate-dependent transhydrogenase activity by a combination of membrane fractions from $u n c A^{-}$and $u n c B^{-}$mutant strains of Escherichia coli K12. Biochemical Journal 134, 1015-1021.

JoNES, I. G. \& MIDGLeY, M. (1985). Expression of a plasmid borne ethidium resistance determinant from Staphylococcus in Escherichia coli: evidence for an efflux system. FEMS Microbiology Letters 28, 355358.

KASHKET, E. R. (1985). The proton motive force in bacteria: a critical assessment of methods. Annual Review of Microbiology 39, 210-242.

Kushner, D. J. \& Khan, S. R. (1968). Proflavine uptake and release in sensitive and resistant Escherichia coli. Journal of Bacteriology 96, 1103-1114.

LAMBert, B. \& LE PECQ, J.-B. (1984). Effect of mutation, electric membrane potential, and metabolic inhibitors on the accessibility of nucleic acids to ethidium bromide in Escherichia coli cells. Biochemistry 83, 166-176.

Midgley, M. \& Dawes, E. A. (1973). The regulation of transport of glucose and methyl $\alpha$-glucoside in Pseudomonas aeruginosa. Biochemical Journal 132, 141-154.

Midgley, M., Parish, M. \& Dawes, E. A. (1985). Interaction of phosphonium ions with Arthrobacter globiformis: evidence for the operation of an efflux system. FEMS Microbiology Letters 30, 7-10.

Midgley, M., Iscandar, N. S. \& Dawes, E. A.
$(1986 a)$. The interaction of phosphonium ions with Acinetobacter calcoaceticus: evidence for the operation of an efflux system. Biochimica et biophysica acta 856, 45-49.

Midgley, M., Iscandar, N. S., Parish, M. \& Dawes, E. A. $(1986 b)$. A fluorescent probe for a phosphonium ion efflux system in bacteria. FEMS Microbiology Letters 34, 187-190.

NAKAMURA, H. (1965). Gene-controlled resistance to acriflavine and other basic dyes in Escherichia coli. Journal of Bacteriology 90, 8-14.

NaKamuRA, H. (1966). Acriflavine-binding capacity of Escherichia coli in relation to acriflavine sensitivity and metabolic activity. Journal of Bacteriology 92 , 1447-1452.

NaKamuRA, H. (1967). Changes in sensitivity to acriflavine of Escherichia coli grown in media of different glucose contents. Journal of General Microbiology 49, 443-449.

ROTTENBERG, H. (1975). The measurement of transmembrane electrochemical proton gradients. Journal of Bioenergetics 7, 61-74.

Silver, S., Levine, E. \& Spielman, P. M. (1968). Acridine binding by Escherichia coli: $\mathrm{pH}$ dependency and strain differences. Journal of Bacteriology 95, 333-359.

ZARITSKY, A., KiHARA, M. \& MACNAB, R. M. (1981). Measurement of membrane potential in Bacillus subtilis: a comparison of lipophilic cations, rubidium ion and a cyanine dye as probes. Journal of Membrane Biology 63, 215-231. 